\title{
Pneumonia after cardiac surgery: Experience of the National Institutes of Health/Canadian Institutes of Health Research Cardiothoracic Surgical Trials Network
}

\author{
Gorav Ailawadi, MD, ${ }^{a}$ Helena L. Chang, MS, ${ }^{\mathrm{b}}$ Patrick T. O’Gara, MD, ${ }^{\mathrm{c}}$ Karen O'Sullivan, MPH, \\ Y. Joseph Woo, MD, ${ }^{d}$ Joseph J. DeRose, Jr, MD, ${ }^{e}$ Michael K. Parides, PhD, ${ }^{\mathrm{b}}$ Vinod H. Thourani, MD, ${ }^{\mathrm{f}}$ \\ Sophie Robichaud, RT, ${ }^{\mathrm{g}}$ A. Marc Gillinov, MD, ${ }^{\mathrm{h}}$ Wendy C. Taddei-Peters, PhD, ${ }^{\mathrm{i}}$ Marissa A. Miller, DVM, \\ Louis P. Perrault, MD, ${ }^{\mathrm{g}}$ Robert L. Smith, MD ${ }^{\mathrm{j}}$ Lyn Goldsmith, RN, ${ }^{\mathrm{k}}$ Keith A. Horvath, MD, \\ Kristen Doud, PhD, ${ }^{\mathrm{m}}$ Kim Baio, RN, ${ }^{\mathrm{f}}$ Annetine C. Gelijns, PhD, ${ }^{\mathrm{b}}$ Alan J. Moskowitz, MD, ${ }^{\mathrm{b}}$ \\ Emilia Bagiella, PhD, ${ }^{\mathrm{b}}$ John H. Alexander, MD, MHS, ${ }^{\mathrm{n}}$ and Alexander Iribarne, MD, MS
}

\begin{abstract}
Rationale: Pneumonia remains the most common major infection after cardiac surgery despite numerous preventive measures.

Objectives: To prospectively examine the timing, pathogens, and risk factors, including modifiable management practices, for postoperative pneumonia and estimate its impact on clinical outcomes.

Methods: A total of 5158 adult cardiac surgery patients were enrolled prospectively in a cohort study across 10 centers. All infections were adjudicated by an independent committee. Competing risk models were used to assess the association of patient characteristics and management practices with pneumonia within 65 days of surgery. Mortality was assessed by Cox proportional hazards model and length of stay by a multistate model.
\end{abstract}

Measurements and Main Results: The cumulative incidence of pneumonia was $2.4 \%, 33 \%$ of which occurred after discharge. Older age, lower hemoglobin level, chronic obstructive pulmonary disease, steroid use, operative time, and left ventricular assist device/heart transplant were risk factors. Ventilation time (24-48 vs $\leq 24$ hours; hazard ratio [HR], 2.83; 95\% confidence interval [95\% CI], 1.724.66; $>48$ hours HR, 4.67; 95\% CI, 2.70-8.08), nasogastric tubes (HR, 1.80; 95\% CI, 1.10-2.94), and each unit of blood cells transfused (HR, 1.16; 95\% CI, 1.081.26 ) increased the risk of pneumonia. Prophylactic use of second-generation cephalosporins (HR, 0.66; 95\% CI, 0.45-0.97) and platelet transfusions (HR, 0.49, 95\% CI, 0.30-0.79) were protective. Pneumonia was associated with a marked increase in mortality (HR, 8.89; 95\% CI, 5.02-15.75) and longer length of stay of $13.55 \pm 1.95$ days (bootstrap 95\% CI, 10.31-16.58).

Conclusions: Pneumonia continues to impose a major impact on the health of patients after cardiac surgery. After we adjusted for baseline risk, several specific management practices were associated with pneumonia, which offer targets for quality improvement and further research. (J Thorac Cardiovasc Surg 2017;153:1384-91)

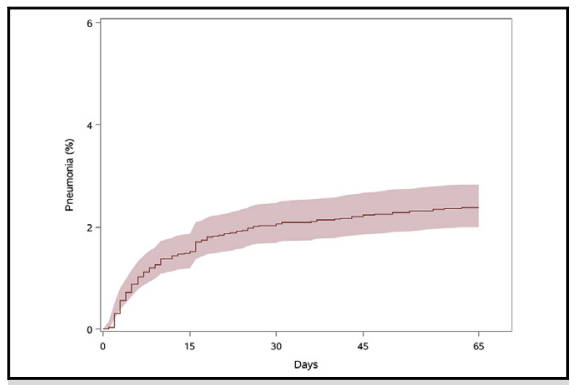

Cumulative incidence of pneumonia over 65 days.

\section{Central Message}

Pneumonia is the most common infection after cardiac surgery. Several specific modifiable management practices were associated with pneumonia, which offer targets for quality improvement.

\section{Perspective}

Pneumonia is a common complication after cardiac surgery, and previous studies have identified several patient-specific risk factors. Ours, however, is the first multicenter, prospective study of both risk factors and management practices on the risk of pneumonia. This analysis provides knowledge and targets for future quality improvement initiatives.

See Editorial Commentary page 1392.

\footnotetext{
From ${ }^{\mathrm{a} C a r d i o t h o r a c i c ~ S u r g e r y, ~ U n i v e r s i t y ~ o f ~ V i r g i n i a, ~ C h a r l o t t e s v i l l e, ~ V a ; ~}{ }^{\mathrm{b}}$ Population Health Science and Policy, Icahn School of Medicine at Mount Sinai; ${ }^{\mathrm{c} C a r d i o-}$ vascular Medicine, Brigham and Women's Hospital, Boston, Mass; ${ }^{\mathrm{d} D e p a r t m e n t ~ o f ~}$ Cardiothoracic Surgery, Stanford University, Stanford, Calif; ${ }^{\mathrm{e}}$ Cardiovascular and Thoracic Surgery, Montefiore-Einstein Heart Center, Bronx, NY; ${ }^{\mathrm{f}}$ Cardiothoracic Surgery, Emory University Hospital Midtown, Atlanta, Ga; ${ }^{\mathrm{g}}$ Montreal Heart Institute, Montreal, Canada; ${ }^{\mathrm{h} T h o r a c i c ~ a n d ~ C a r d i o v a s c u l a r ~ S u r g e r y, ~ C l e v e l a n d ~ C l i n i c, ~}$ Cleveland, Ohio; ${ }^{i}$ Division of Cardiovascular Sciences, National Heart, Lung, and Blood Institute; ${ }^{j}$ Cardiac Surgery, The Heart Hospital Baylor Plano, Plano, Tex; ${ }^{k}$ Division of Cardiothoracic Surgery, Columbia University Medical Center, New York, NY; ${ }^{\mathrm{I}} \mathrm{NIH}$ Heart Center at Suburban Hospital, Bethesda, Md; ${ }^{\mathrm{m}}$ Cardiothoracic Research, Cleveland Clinic; ${ }^{\mathrm{n} D i v i s i o n}$ of Cardiology and Duke Clinical Research Institute, Duke Medicine, Durham, NC; and ${ }^{\circ}$ Cardiac Surgery, Dartmouth-Hitchcock Medical Center, Lebanon, $\mathrm{NH}$.
}

\footnotetext{
A cooperative agreement (U01 HL088942) funded by the National Heart, Lung, and Blood Institute and the National Institute of Neurological Disorders and Stroke of the National Institutes of Health and the Canadian Institutes of Health Research. The views expressed in this article are those of the authors and do not necessarily represent the views of the National Heart, Lung, and Blood Institute; National Institutes of Health; or the United States Department of Health and Human Services. Clinical Trial Registry Number: NCT01089712

Received for publication July 27, 2016; revisions received Nov 16, 2016; accepted for publication Dec 28, 2016; available ahead of print March 21, 2017.

Address for reprints: Annetine C. Gelijns, PhD, Department of Population Health Science and Policy, Icahn School of Medicine at Mount Sinai, One Gustave L Levy Place, Box 1077, New York, NY 10029 (E-mail: Annetine.gelijns@mssm.edu). $0022-5223 / \$ 36.00$

Copyright (c) 2017 by The American Association for Thoracic Surgery http://dx.doi.org/10.1016/j.jtcvs.2016.12.055
} 


\section{Abbreviations and Acronyms \\ $\mathrm{CI}=$ confidence interval \\ COPD $=$ chronic obstructive pulmonary disease \\ CTSN $=$ Cardiothoracic Surgical Trials Network \\ HAI = healthcare-associated infection \\ HR = hazard ratio \\ LOS = length of stay \\ $\mathrm{NG}=$ nasogastric \\ SCIP $=$ Surgical Care Improvement Project}

\section{Scanning this QR code will take you to the online appendices for this article.}

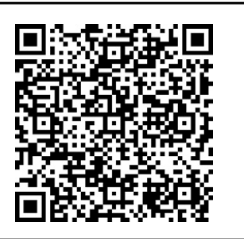

Healthcare-associated infections (HAIs) represent the leading cause of noncardiac morbidity after cardiac surgery, ${ }^{1}$ and pneumonia particularly is common and responsible for adverse patient outcomes. ${ }^{2-4}$ Moreover, pneumonia frequently is cited as among the most costly and resourceintensive of all HAIs. ${ }^{5-7}$

Patients undergoing cardiac surgery are highly susceptible to pneumonia. Many patients present with cardiac symptoms requiring hospitalization before urgent surgery, predisposing them to pathogens. Common risk factors among cardiac surgery patients, such as chronic obstructive pulmonary disease (COPD), heart failure, and advanced age, result in a greater risk profile for pneumonia. Moreover, cardiopulmonary bypass, with its effect on systemic inflammatory mediators and its potential for lung injury, may further contribute to the risk of developing pneumonia. ${ }^{8}$ Significant fluid shifts in the perioperative setting often leading to pulmonary edema, combined with the frequent need for transfusion of blood products, may affect a patient's risk for pneumonia. ${ }^{9}$ Any prolonged use of mechanical ventilation also places patients at increased risk for pneumonia. ${ }^{10,11}$ Finally, postoperative pain due to sternotomy or thoracotomy can affect pulmonary mechanics. Variations in management practices, such as fluid administration and ventilator management, are likely to affect the incidence of pneumonia, ${ }^{12,13}$ but few insights exist about the relationship between these "process of care" variables and pneumonia.

The purpose of this study was to examine the time course, pathogens, and risk factors, including modifiable management practices, for postoperative pneumonia in patients undergoing cardiac surgery. This study is a substudy of a larger prospective cohort study conducted within centers participating in the Cardiothoracic Surgical Trials Network (CTSN), looking at all serious postoperative infections. ${ }^{14}$

\section{PATIENTS AND METHODS Study Design and Patients}

The primary objective of this CTSN observational study was to identify management practices associated with the risk of infection after cardiac surgery. This study was conducted in 10 centers from the CTSN. The patient population included all adults receiving cardiac surgical interventions, excluding those with active systemic infections, including endocarditis.

We targeted a minimum sample size of 5000 patients to obtain at least 200 patients with major infections. This sample size was based not on explicit statistical criteria but on acquiring an adequate number of events (at least 10 per variable) to ensure stability of coefficient estimates in our models. ${ }^{15,16}$ Patients were followed for up to $60 \pm 5$ days after surgery, with 2 planned postdischarge assessments at 30 and 60 days after surgery; the last date of follow-up was November 29, 2010. We collected data on patient characteristics (demographics, baseline laboratory values, comorbidities), surgery-related factors (such as previous intra-aortic balloon pump, surgery time, operative procedure), and management practices (such as antimicrobial prophylaxis, glycemic control, line management) (see Appendix E1). Data were transmitted from sites electronically to a secure server administered by the Data Coordinating Center. Participating institutional review boards approved the protocol (see Appendix E2 for participating sites), and the study was overseen by a National Heart, Lung, and Blood Institute-appointed Data Safety and Monitoring Board. All patients provided written informed consent to participate and release their medical information.

\section{Endpoints}

The primary endpoint for this analysis was pneumonia within 65 days of the index cardiac surgery. Pneumonia was classified according to definitions from the Centers for Disease Control and the National Healthcare Safety Network surveillance (see Appendix E1). Other secondary endpoints included all-cause mortality, reoperation, and hospital readmissions. All pneumonias were reviewed by an independent event adjudication committee. The date of final event adjudication was June 2011.

\section{Data Analysis}

We used the proportional subdistribution hazards model,,${ }^{17}$ a variant of the Cox proportional hazards model, to account for death as a competing event when assessing the effect of baseline characteristics and management practices on pneumonia. Model building proceeded in 2 stages. We first identified patient- and procedure-related risk factors that were associated individually (at $P<.10$ ) with pneumonia and remained significant (at $P<.05)$ in the multivariable model using a backward selection procedure. We then evaluated the additional contribution of management practices used before the first pneumonia (see Appendix E1 for details), except for postoperative transfusions, where the exact timing could not always be ascertained. Management practices that were associated individually with pneumonia (at $P<.10$ ) were placed in a multivariable model that contained all the patient- and procedure-specific variables in the first stage. With the use of a backward selection approach, the final competing risk model for pneumonia consisted of only management practices with a $P<.05$, adjusting for all the first stage baseline risk factors.

The standard Cox proportional hazards model was applied to the mortality analysis, with pneumonia treated as a time-dependent covariate. Patient characteristics that are known risk factors for mortality in the elderly cardiac surgery population and that were significant in our model were controlled for in the analysis.

To estimate the incremental length of stay (LOS) due to pneumonia, we used a multistate approach that treats pneumonia as a time-dependent exposure and mortality as a competing risk. ${ }^{18}$ LOS was defined as the time from index procedure to hospital discharge or death. The model assumed a timeinhomogeneous Markov process with 1 initial state (index surgery), 1 intermediate state (pneumonia), and 2 absorbing states (death and discharged 
alive). All patients started in the initial state and could transition to the other states. Patients who developed pneumonia could have had a previous or subsequent infection, and patients who did not develop pneumonia could have had other infections. A bootstrap standard error and $95 \%$ confidence interval (CI) was computed for the additional LOS due to pneumonia based on 1000 bootstrap samples. All analyses were done in SAS statistical software (SAS v9.4; SAS Institute, Cary, NC) and R 3.1.1. ${ }^{19,20}$

\section{RESULTS}

\section{Patients Characteristics}

Among the patients enrolled $(\mathrm{n}=5158)$, the mean age was $64.4 \pm 13.2$ years, the median body mass index was $28.2 \mathrm{~kg} / \mathrm{m}^{2}$, and the proportion of women was $33 \%$ $(\mathrm{n}=1708$; Table 1). Diabetes was present in $23 \%$ $(\mathrm{n}=1169)$ of patients, $29 \%(\mathrm{n}=1505)$ had heart failure, and $14 \%(n=746)$ had COPD of mild or greater severity. Nineteen percent $(n=958)$ of patients had undergone previous cardiac surgery. The most common procedures were isolated coronary artery bypass grafting $(33 \%, \mathrm{n}=1677)$ and isolated valve surgery $(36 \%, \mathrm{n}=1878)$.

\section{Frequency and Timing of Pneumonia and Microorganisms}

A total of 123 patients experienced 125 pneumonia events (crude cumulative incidence $2.4 \%$, Figure $1, A$ ), accounting for $41.5 \%$ of all major infections $(\mathrm{n}=301)$ in this cohort (Figure 1, $A$ ). The initial diagnosis was made during the index hospitalization in $67 \%(n=82)$ of patients who developed pneumonia, nearly one half of which $(n=58)$ occurred during the first week after surgery. The mean time to the first episode of pneumonia was 14.4 days, with a median time of 8 days (range 1-62). Of the 123 patients who experienced pneumonia, $106(86 \%)$ contracted it within 30 days after cardiac surgery.

The distribution of microorganisms isolated from patients who developed pneumonia is shown in Figure 2. The 3 most common isolates were Pseudomonas aeruginosa $(15.8 \%, \mathrm{n}=15)$, Klebsiella pneumonia $(11.6 \%$, $\mathrm{n}=11)$, and Enterobacter cloacae $(10.5 \%, \mathrm{n}=10)$.

\section{Baseline Risk Factors Related to Pneumonia}

Preoperative patient characteristics that were associated with a greater risk of pneumonia in multivariable analysis included older age (hazard ratio [HR], 1.02; 95\% CI, 1.00$1.03 ; P=.05$ ), presence of COPD (HR, 2.17; 95\% CI, $1.47-3.21 ; P<.001)$, and recent steroid use (HR, 1.91; 95\% CI, 1.01-3.59; $P=.05)$. Greater hemoglobin levels at baseline were protective ( $\mathrm{HR}, 0.88 ; 95 \% \mathrm{CI}, 0.79$ $0.97 ; P=.01$ ) (Table 2). Smoking history did not increase the risk of pneumonia in the multivariable model. Approximately $50 \%$ of patients were admitted on the same day of
TABLE 1. Patient and operative characteristics*

\begin{tabular}{|c|c|}
\hline Baseline and operative characteristics & $\begin{array}{c}\text { Overall } \\
(\mathbf{N}=\mathbf{5 1 5 8})\end{array}$ \\
\hline \multicolumn{2}{|l|}{ Demographics } \\
\hline Age, mean (SD) & $64.4(13.2)$ \\
\hline Male & $3450(66.9)$ \\
\hline White & $4322(83.9)$ \\
\hline BMI & $28.2(25.1-32.3)$ \\
\hline \multicolumn{2}{|l|}{ Insurance } \\
\hline Medicaid & $233(4.5)$ \\
\hline Medicare & $1928(37.5)$ \\
\hline Government (other) & $626(12.2)$ \\
\hline Private & $2099(40.8)$ \\
\hline None/self & $260(5.1)$ \\
\hline \multicolumn{2}{|l|}{ Baseline laboratory values } \\
\hline $\mathrm{WBC}, \times 10^{3} / \mathrm{mL}$ & $7.0(5.7-8.4)$ \\
\hline Creatinine, $\mathrm{mg} / \mathrm{dL}$ & $1.0(0.8-1.2)$ \\
\hline Hemoglobin, g/dL & $13.4(12.0-14.5)$ \\
\hline \multicolumn{2}{|l|}{ Cardiac morbidity } \\
\hline Heart failure & $1505(29.2)$ \\
\hline Ejection fraction & $55.0(48.0-60.0)$ \\
\hline Previous cardiac surgery & $958(18.6)$ \\
\hline \multicolumn{2}{|l|}{ Noncardiac morbidity } \\
\hline Corticosteroids & $176(3.4)$ \\
\hline Diabetes $\dagger$ & $1169(22.7)$ \\
\hline \multicolumn{2}{|l|}{ COPD } \\
\hline None & $4412(85.5)$ \\
\hline Mild or moderate & $644(12.5)$ \\
\hline Severe & $102(2.0)$ \\
\hline \multicolumn{2}{|l|}{ Operative } \\
\hline Surgery time, $\mathrm{h}$ & $4.2(3.3-5.2)$ \\
\hline Bypass time, $\min \ddagger$ & $105.0(78.0-140.0)$ \\
\hline Sternotomy & $4669(90.5)$ \\
\hline \multicolumn{2}{|l|}{ Surgery type } \\
\hline Elective & $3806(73.8)$ \\
\hline Urgent & $1214(23.5)$ \\
\hline Emergent & $138(2.7)$ \\
\hline \multicolumn{2}{|l|}{ Procedure } \\
\hline Isolated CABG & $1677(32.5)$ \\
\hline Isolated valve & $1878(36.4)$ \\
\hline $\mathrm{CABG}+$ valve & $692(13.4)$ \\
\hline LVAD/Tx & $122(2.4)$ \\
\hline Thoracic aortic & $428(8.3)$ \\
\hline Other $\S$ & $361(7.0)$ \\
\hline
\end{tabular}

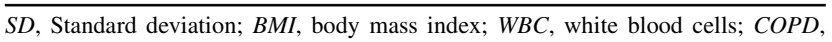
chronic obstructive pulmonary disease; $C A B G$, coronary artery bypass grafting; $L V A D / T x$, left ventricular assist device or heart transplant surgery. *Continuous variables are expressed as median (interquartile range) and categorical variables as count (\%). $\dagger$ Insulin or oral medications. $\ddagger$ A total of $91.1 \%$ of patients had on-pump surgical procedures. §Other: ventricular septal defect repairs, atrial septal defect repairs, aneurysmectomies, patent foramen ovale closures, ablations, septal myectomies, excision of cardiac tumors, pericardiectomies, and limited other procedures.

surgery, and the majority of the other patients were admitted within 1 week before surgery. Preoperative LOS was not associated with the development of pneumonia after we accounted for other risk factors. Operative 


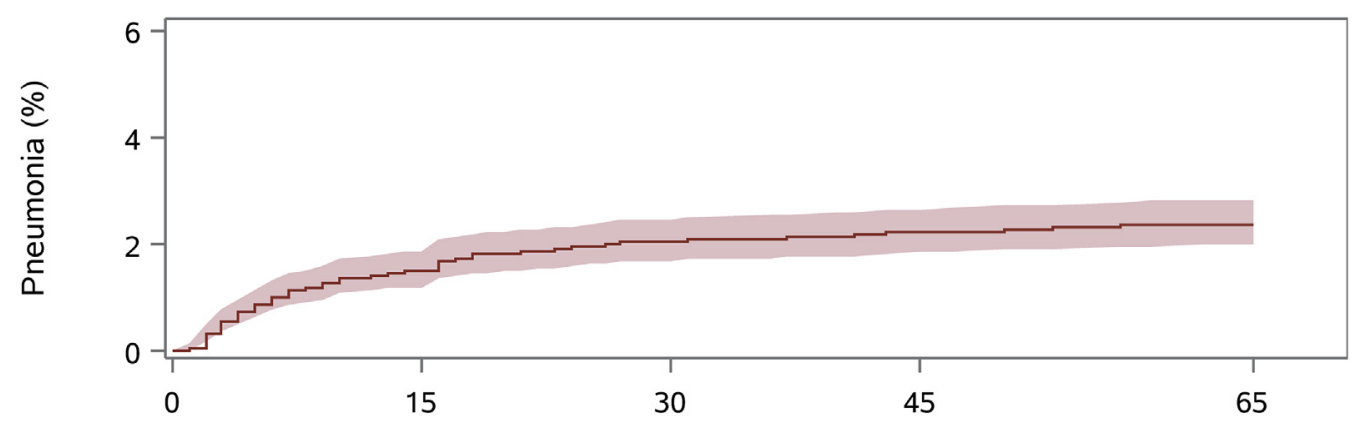

A

Days

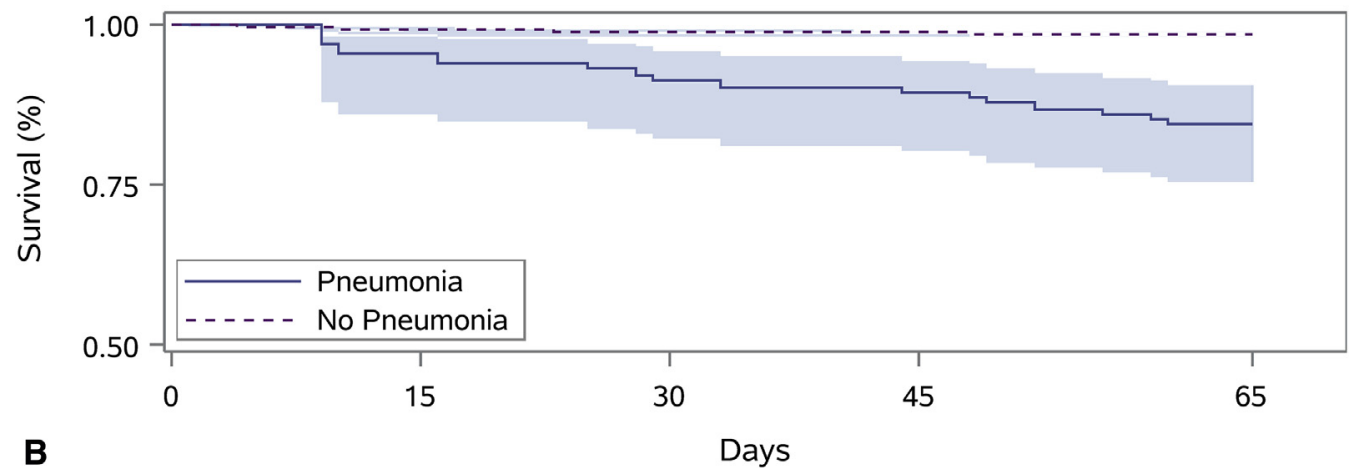

FIGURE 1. A, Cumulative incidence function with $95 \%$ confidence intervals for pneumonia with death as a competing risk. B, Extended Kaplan-Meier curve with $95 \%$ confidence intervals for mortality based on method of Snappin and colleagues. ${ }^{20}$

variables associated with greater pneumonia risk included left ventricular assist device implantation or heart transplantation (HR, 2.79; 95\% CI, 1.50-5.17; $P=.001$ ), and longer operative time (HR, $1.38 ; 95 \%$ CI, 1.25-1.53; $P<.001)$.

\section{Management Practices Related to Pneumonia}

When we controlled for baseline risk factors, management practices that were associated with an increased risk of pneumonia included the use of a nasogastric (NG) tube postoperatively (HR, 1.80; 95\% CI, 1.10-2.94; $P=.02$ ), and transfusion of packed red blood cells (for each unit: HR, 1.16; 95\% CI, 1.08-1.26; $P<.001$; Table 3). Platelet transfusion, however, was protective (HR, $0.49,95 \% \mathrm{CI}$, $0.30-0.79, P=.004)$. Compared with postoperative ventilation of 24 hours or less, an intubation time of 24 to 48 hours was associated with more than double the risk of pneumonia (HR, 2.83; 95\% CI, 1.72-4.66; $P<.001$ ) and ventilation exceeding 48 hours was associated with more than a 4-fold greater risk (HR, 4.67; 95\% CI, 2.70-8.08; $P<.001)$. Perioperative second-generation cephalosporins (cefuroxime, cefoxitin, with or without concomitant vancomycin), which were used in $47 \%$ of patients, reduced the risk of pneumonia by more than $30 \%$ ( $\mathrm{HR}, 0.66 ; 95 \% \mathrm{CI}$, $0.45-0.97 ; P=.04)$. There was consistent use of head of bed elevation and secretion management postoperatively and thus, neither affected pneumonia risk. Placement of femoral lines, number of central lines, and hyperglycemia were not significant predictors in the multivariable model.

\section{LOS and Readmissions}

The observed mean LOS after the initial surgical procedure was $32.4 \pm 22.6$ days for patients with pneumonia during the index hospitalization compared with $8.9 \pm 6.5$ days for those without it. After their index surgery, patients who developed pneumonia stayed in the hospital for nearly 2 weeks longer (excess LOS: $13.55 \pm 1.95$ days; bootstrap 95\% CI, 10.31-16.58). In the overall parent cohort study, the readmission rate was $19 \%(\mathrm{n}=945)$. Infection was the most common reason for readmission $(16 \%$ of all readmissions) and pneumonia constituted $21.3 \%$ of this group.

\section{Pneumonia and Mortality}

Ninety-seven patients $(1.9 \%)$ died during follow-up, with one half of the deaths occurring within 19 days of index surgery. Figure $1, B$ depicts the unadjusted time-varying effect of pneumonia on mortality. Pneumonia was associated with a markedly greater risk of death (HR, 8.89; 95\% CI, 5.02-15.75; $P<.001$ ), after we adjusted for patient's age, sex, comorbidities (diabetes and 


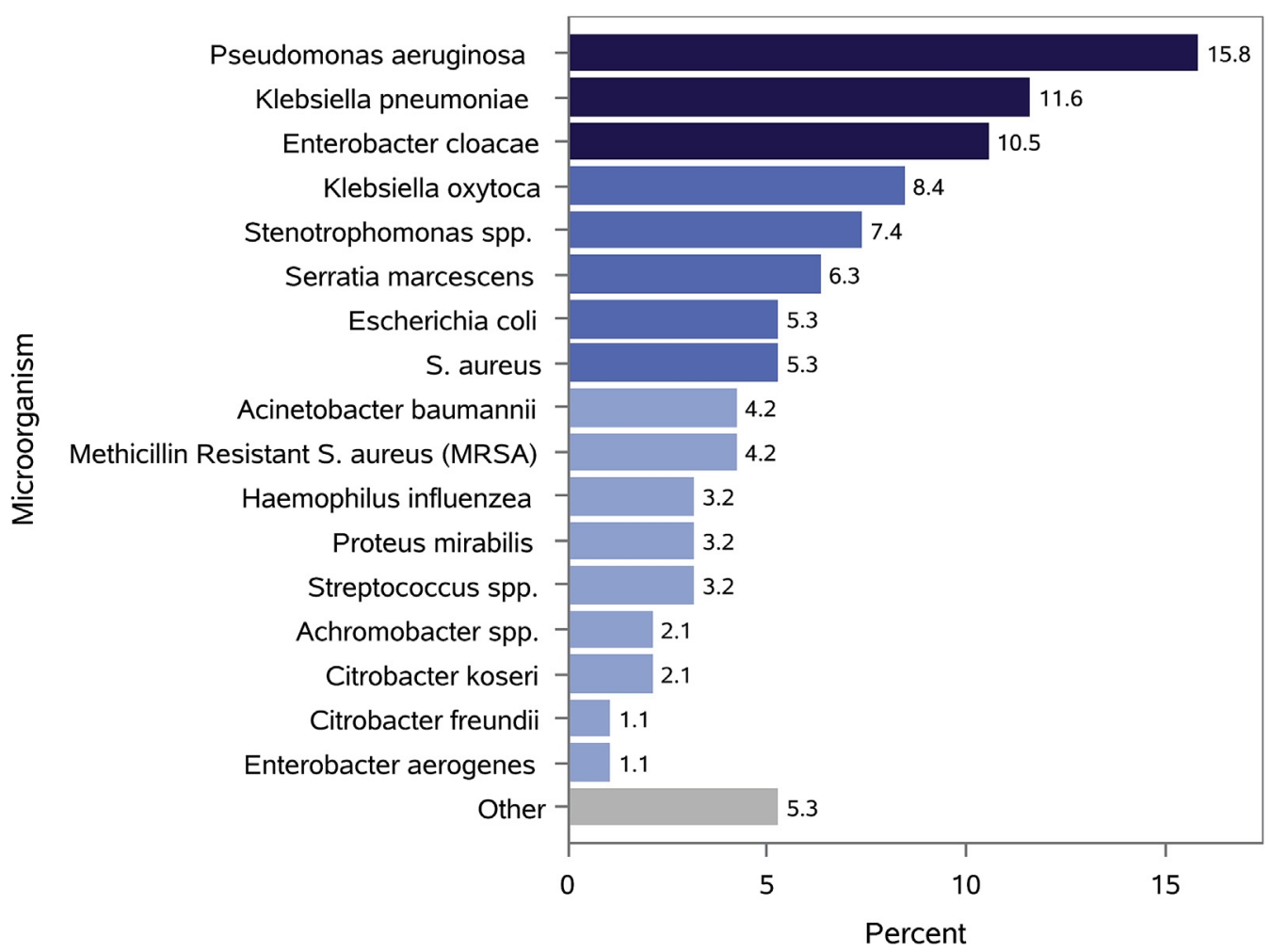

FIGURE 2. Distribution of identified microorganisms among patients developing pneumonia organism data was available for $62 \%$ of pneumonia cases. Up to different 3 organisms was recorded for each event. Other categories: Neisseria sicca, Alcaligenes xylosoxidans, Corynebacterium pseudodiptheriticum, Morganella morganii, and Serratia plymuthica.

congestive heart failure), and baseline hemoglobin and creatinine levels (Table 4). The 65-day mortality rates (per 100 patient-months) for patients with and without pneumonia were 6 and 0.8 , respectively.

\section{COMMENT}

In this large, multicenter, prospective cohort study, postoperative pneumonia was the most common infection that occurred within 65 days, with more than $30 \%$ of first events diagnosed after discharge from the index hospitalization. ${ }^{14}$ Older age, COPD, steroid use, lower hemoglobin levels, left ventricular assist device/heart transplants, and longer

TABLE 2. Patient and procedure characteristics associated with pneumonia

\begin{tabular}{lcc}
\hline \multicolumn{1}{c}{ Baseline variable } & HR $(\mathbf{9 5} \% \mathbf{C I})$ & $\boldsymbol{P}$ value \\
\hline Age, y & $1.02(1.00-1.03)$ & .05 \\
COPD, yes/no & $2.17(1.47-3.21)$ & $<.001$ \\
Corticosteroids, yes/no & $1.91(1.01-3.59)$ & .05 \\
Hemoglobin, g/dL & $0.88(0.79-0.97)$ & .01 \\
LVAD/Tx, yes/no & $2.79(1.50-5.17)$ & .001 \\
Duration of surgery, h & $1.38(1.25-1.53)$ & $<.001$ \\
\hline
\end{tabular}

$H R$, Hazard ratio; $C I$, confidence interval; $C O P D$, chronic obstructive pulmonary disease; $L V A D / T x$, left ventricular assist device or heart transplant surgery. duration of surgery were significantly associated with risk of pneumonia. Importantly, the use of second-generation cephalosporins for perioperative prophylaxis, shorter ventilation time ( $<24$ hours), avoidance of NG tube use, fewer packed red blood cell transfusions, and receipt of platelet transfusions were all associated with a decreased risk of postoperative pneumonia. Ultimately, postoperative pneumonia was associated with a nearly 9 -fold increase in mortality and an additional 2 weeks of index hospital stay.

\section{Impact of Pneumonia in Cardiac Surgery}

Traditionally, surgical-site infections have been perceived as the most common infection after cardiac surgery. Our study reveals pneumonia to be the most common serious infection after cardiac surgery, and this finding is supported by other contemporary studies. ${ }^{14,21}$ In a recent analysis of more than 19,000 patients, pneumonia was the most common postoperative infection $(6 \%)$ whereas deep surgical-site infections occurred in just $1 \% .{ }^{22}$ In the present study, pneumonia was associated with an 8.9 -fold increased risk of mortality even after we adjusted for baseline patient characteristics and resulted in a 65-day pneumonia mortality rate of 6 per 100 patient-months. 
TABLE 3. Management practices associated with pneumonia

\begin{tabular}{lcc}
\hline \multicolumn{1}{c}{ Management practice* } & HR $(\mathbf{9 5} \%$ CI $)$ & $\boldsymbol{P}$ value \\
\hline Second-generation CEPH, yes/no & $0.66(0.45-0.97)$ & .04 \\
Ventilation (vs $\leq 24$ h) & & \\
$\quad 24-48$ h & $2.83(1.72-4.66)$ & $<.001$ \\
$>48$ h & $4.67(2.70-8.08)$ & $<.001$ \\
NG tube, yes/no & $1.80(1.10-2.94)$ & .02 \\
PRBC, unit & $1.16(1.08-1.26)$ & $<.001$ \\
Platelet, yes/no & $0.49(0.30-0.79)$ & .004 \\
\hline
\end{tabular}

$H R$, Hazard ratio; $C I$, confidence interval; $C E P H$, cephalosporin; $N G$, nasogastric tube; $P R B C$, packed red blood cells. *Model adjusted for baseline risk factors in Table 2.

In addition to the effect on morbidity and mortality, pneumonia represents a significant burden on resource use. Our group has estimated the incremental cost associated with a major HAI to be $\$ 38,000$, with infection-related readmissions costing 3 times that of readmissions that were unrelated to infection. ${ }^{23}$ There have been few publications that focus on the economic impact of pneumonia (compared with undefined pneumonitis) in the cardiac surgery population. A recent analysis that used the Nationwide Inpatient Sample in patients undergoing isolated mitral valve surgery estimated an average net increase in hospital cost of $\$ 29,692$ for the $5.5 \%$ of individuals with postoperative pneumonia and an increase in the median LOS of 10 days. ${ }^{24}$ Thus, postoperative pneumonia represents not only a significant risk factor for morbidity and mortality but also a significant driver of resource use.

\section{Timing of Pneumonia}

In comparison with the published literature, which focuses mostly on the index hospitalization or on 30-day follow-up, patients in this study were followed for up to 65 days after the index operation. As such, this study revealed that a substantial proportion of first pneumonia events (more than 30\%) occurred after the index hospitalization, and $14 \%$ more than 30 days postsurgery.

Although it would be expected that the majority of cases of pneumonia would manifest early in the postoperative setting due to postoperative pain, need for narcotics, and

TABLE 4. Impact of pneumonia on mortality

\begin{tabular}{lcc}
\hline \multicolumn{1}{c}{ Variable } & HR $(\mathbf{9 5} \% \mathbf{C I})$ & $\boldsymbol{P}$ value \\
\hline Pneumonia & $8.89(5.02-15.75)$ & $<.001$ \\
Age, y & $1.03(1.01-1.05)$ & $<.001$ \\
Male & $0.60(0.39-0.91)$ & .02 \\
Diabetes, ${ }^{*}$ yes/no & $1.57(1.03-2.41)$ & .04 \\
Heart failure, yes/no & $1.86(1.24-2.80)$ & .003 \\
Creatinine, mg/dL & $1.17(1.06-1.30)$ & .002 \\
Hemoglobin, g/dL & $0.85(0.75-0.95)$ & .005 \\
\hline
\end{tabular}

$H R$, Hazard ratio; $C I$, confidence interval. *Insulin or oral medications. fluid shifts, there are some potential reasons why pneumonia may develop later. Because the average LOS for many routine cardiac operations is 5 to 7 days, retrospective studies may underestimate the true prevalence of pneumonia. It is likely that the intensive pulmonary care that occurs in the hospital is not maintained after discharge. Also, many "late" pneumonias (after the first week) in our study occurred in patients with prolonged hospitalizations and/or difficult postoperative courses with multiple complications.

\section{Modifiable Processes of Care}

Given the significant association with mortality and increased resource use, there has been a strong effort during the past decade to reduce HAIs through improvements in management practices. This prospective study was the first to our knowledge to investigate the relationship between processes of care and the incidence of postoperative pneumonia after cardiac operations. National guidelines have been developed and implemented to avert infections, and among these is the Surgical Care Improvement Project (SCIP). ${ }^{25}$ The SCIP guidelines include standardizing perioperative antibiotic use to decrease postoperative surgical-site infections. Specific SCIP measures addressing the risk of infection include (1) the administration of appropriate antibiotics within 60 minutes of incision, (2) discontinuation of antibiotics within 48 hours after cardiac surgery, and (3) controlled blood glucose $(<200 \mathrm{mg} / \mathrm{dL})$ at $6 \mathrm{AM}$ postoperative day one. The Society of Thoracic Surgeons also has published practice guidelines related to antibiotic prophylaxis. ${ }^{26}$ In these guidelines, firstor second-generation cephalosporins are considered firstline therapy for prophylaxis with no clear data supporting first-generation over second-generation cephalosporins. In patients with significant allergy to $\beta$-lactam antibiotics, vancomycin with or without an aminoglycoside is recommended. In multivariable analysis, the use of secondgeneration cephalosporins with broader Gram-negative coverage was associated with a lower risk of pneumonia; however, neither first- nor second-generation cephalosporins have activity against Pseudomonas, which was the most common organism observed in patients with pneumonia. Therefore, consideration might be given to optimizing perioperative antibiotic regimens for patients who may be high risk for developing postoperative pneumonia, although any recommendation of this type needs to be balanced carefully against the risk of promoting the emergence of multidrug-resistant nosocomial organisms.

Numerous studies have shown that prolonged intubation affects postoperative pneumonia, LOS, and complications. As such, early extubation after surgery has been a prominent focus of cardiac surgical quality improvement for 
several years, often with reimbursement linked to postoperative extubation time. The present study reinforces the importance of timely postoperative extubation, with patients intubated between 24 and 48 hours or $>48$ hours having 2.83- and 4.67-fold increased risk of pneumonia, respectively, compared with patients who are extubated within 24 hours. Likewise, we have demonstrated previously the dose-dependent association between red blood cell transfusion and risk of postoperative infections and, as such, efforts need to continue to improve blood conservation in cardiac surgery. ${ }^{27}$

The use of a NG tube was associated with risk of pneumonia. Previous reports have supported this finding. A randomized study comparing the use of an NG tube to no NG tube after cardiac surgery demonstrated no benefit to routine NG use. ${ }^{28}$ Another study identified the use of an NG tube to be the strongest risk factor for developing nosocomial pneumonia (odds ratio, 6.48 [95\% CI, 2.1119.82]) in patients intubated longer than 72 hours. ${ }^{29}$ The fact that many of the organisms cultured in our study were enteral flora supports this observation. It is possible that some patients who received an NG tube were ill for a long period of time postoperatively and, therefore, the NG tube was a marker of illness severity and not the dominant predisposing factor. Nonetheless, it was surprising that $73 \%$ of all patients in this study had an NG tube after surgery; NG tube management may be an important target for process improvement investigations.

\section{Limitations}

We identified the timing of infections and included in the analysis only those management practices that were used before the diagnosis of pneumonia, except transfusions, the timing of which was sometimes unavailable. We cannot definitively exclude practices that were used on the basis of a suspicion of infection. Absence of an association between pneumonia and head elevation and secretion management reflects the fact that there was nearly uniform adoption of these practices across sites. Randomized trials are challenging to conduct in this area. However, the standardization of infection definitions and data collection procedures, as well as site monitoring and adjudication of infections by an expert committee, improve the validity of this observational study. Finally, although we were able to garner much insight from these 123 patients with pneumonia, the relatively low number of outcome events limits our ability to assess more precisely the impact of all measured process of care variables.

\section{CONCLUSION AND IMPLICATIONS}

In this observational study of cardiac surgical patients, pneumonia was the most prevalent infection and had a significant, deleterious impact on LOS and mortality. We identified various processes of care measures that were associated independently with the development of pneumonia, including choice of antibiotic prophylaxis, the use of an NG tube, length of mechanical ventilation after surgery, and the use of red blood cell and platelet transfusions. Despite substantial efforts to reduce the incidence of surgery-associated pneumonia, gaps remain in the application of quality improvement strategies. Given the high incidence of postdischarge pneumonia, efforts also should be directed towards identifying high risk patients and developing and evaluating transitional programs to address this issue.

\section{Conflict of Interest Statement}

Dr Gillinov reports personal fees from Edwards Lifesciences, personal fees from Medtronic, personal fees from On-X, grants and personal fees from St Jude Medical, personal fees from Abbott, personal fees and other from AtriCure, and personal fees from ClearFlow, outside the submitted work. Dr Alexander reports grants from National Institutes of Health/NHLBI, during the conduct of the study. Dr Smith reports grants from NIH/CTSN, during the conduct of the study, personal fees from Abbott Vascular, personal fees from Edwards Lifesciences, grants from Edwards Lifesciences, personal fees from St Jude, outside the submitted work. All other authors have nothing to disclose with regard to commercial support.

\section{References}

1. He S, Chen B, Li W, Yan J, Wang X, Xiao Y. Ventilator-associated pneumonia after cardiac surgery: a meta analysis and systematic review. J Thorac Cardiovasc Surg. 2014;148:3148-55.

2. Kollef MH, Sharpless L, Vlasnik J, Pasque C, Murphy D, Fraser VJ. The impact of nosocomial infections on patient outcomes following cardiac surgery. Chest. 1997; 112:666-75

3. Klevens RM, Edwards JR, Richards CL Jr, Horan TC, Gaynes RP, Pollock DA, et al. Estimating health care-associated infections and deaths in U.S. hospitals, 2002. Public Health Rep. 2007;122:160-6.

4. Rello J, Ollendorf DA, Oster G, Vera-Llonch M, Bellm L, Redman R, et al. VAP Outcomes Scientific Advisory Group. Epidemiology and outcomes of ventilator-associated pneumonia in a large US database. Chest. 2002;122: 2115-21.

5. Scott RD. The Direct Medical Costs of Healthcare-Associated Infections in U.S. Hospitals and the Benefits of Prevention, 2009. Centers for Disease Control and Prevention, February 2009. Available at: http://www.cdc.gov/HAI/pdfs/hai/ Scott_CostPaper.pdf. Accessed January 5, 2016.

6. Thomas CP, Ryan M, Chapman JD, Stason WB, Tompkins CP, Suaya JA, et al. Incidence and cost of pneumonia in Medicare beneficiaries. Chest. 2012;142: 973-81.

7. Kollef MH, Hamilton CW, Ernst FR. Economic impact of ventilator-associated pneumonia in a large matched cohort. Infect Control Hosp Epidemiol. 2012;33: 250-6.

8. Asimakopoulos G, Smith PL, Ratnatunga CP, Taylor KM. Lung injury and acute respiratory distress syndrome after cardiopulmonary bypass. Ann Thorac Surg. 1999;68:1107-15.

9. Banbury MK, Brizzio ME, Rajeswaran J, Lytle BW, Blackstone EH. Transfusion increases the risk of postoperative infection after cardiovascular surgery. $J \mathrm{Am}$ Coll Surg. 2006;202:131-8.

10. Sheng W, Xing QS, Hou WM, Sun L, Niu ZZ, Lin MS, et al. Independent risk factors for ventilator-associated pneumonia after cardiac surgery. J Invest Surg. 2014;27:256-61. 
11. Allou N, Bronchard R, Guglielminotti J, Dilly MP, Provenchere S, Lucet JC, et al. Risk factors for postoperative pneumonia after cardiac surgery and development of a preoperative risk score*. Crit Care Med. 2014;42:1150-6.

12. Bonten MJ. Healthcare epidemiology: ventilator-associated pneumonia: preventing the inevitable. Clin Infect Dis. 2011;52:115-21.

13. Safdar N, Crnich CJ, Maki DG. The pathogenesis of ventilator-associated pneumonia: its relevance to developing effective strategies for prevention. Respir Care. 2005;50:725-39; discussion 739-41.

14. Gelijns AC, Moskowitz AJ, Acker MA, Argenziano M, Geller NL, Puskas JD, et al. Cardiothoracic Surgical Trials Network (CTSN). Management practices and major infections after cardiac surgery. J Am Coll Cardiol. 2014;64:372-81.

15. Peduzzi P, Concato J, Feinstein AR, Holford TR. Importance of events per independent variable in proportional hazards regression analysis. II. Accuracy and precision of regression estimates. J Clin Epidemiol. 1995;48:1503-10.

16. Harrel FE Jr, Lee KL, Mark DB. Multivariable prognostic models: issues in developing models, evaluating assumptions and adequacy, and measuring and reducing errors. Stat Med. 1996;15:361-87.

17. Fine JP, Gray RJ. A proportional hazards model for the subdistribution of a competing risk. J Am Stat Assoc. 1999;94:496-509.

18. Allignol A, Schumacher M, Beyersmann J. Estimating summary functionals in multistate models with an application to hospital infection data. Comput Stat. 2011;26:181-97.

19. Allignol A, Schumacher M, Beyersmann J. Empirical transition matrix of multi-state models: the etm package. J Stat Softw. 2011;38:1-15.

20. Snappin SM, Jiang Q, Iglewitz B. Illustrating the impact of time varying covariate with an extended Kaplan-Meier estimator. Am Stat. 2005;59:301-7.

21. Likosky DS, Wallace AS, Prager RL, Jacobs JP, Zhang M, Harrington SD, et al. Michigan Society of Thoracic and Cardiovascular Surgeons Quality Collaborative. Sources of variation in hospital-level infection rates after coronary artery bypass grafting: an analysis of the Society of Thoracic Surgeons Adult Heart Surgery Database. Ann Thorac Surg. 2015;100:1570-6.
22. Mocanu V, Buth KJ, Johnston LB, Davis I, Hirsch GM, Légaré JF. The importance of continued quality improvement efforts in monitoring hospital-acquired infection rates: a cardiac surgery experience. Ann Thorac Surg. 2015;99:2061-9.

23. Greco G, Shi W, Michler RE, Meltzer DO, Ailawadi G, Hohmann SF, et al. Costs associated with health care-associated infections in cardiac surgery. J Am Coll Cardiol. 2015;65:15-23.

24. Iribarne A, Burgener JD, Hong K, Raman J, Akhter S, Easterwood R, et al Quantifying the incremental cost of complications associated with mitra valve surgery in the United States. J Thorac Cardiovasc Surg. 2012;143: 864-72.

25. Munday GS, Deveaux P, Roberts H, Fry DE, Polk HC. Impact of implementation of the Surgical Care Improvement Project and future strategies for improving quality in surgery. Am J Surg. 2014;208:835-40.

26. Engelman R, Shahian D, Shemin R, Guy TS, Bratzler D, Edwards F, et al Workforce on Evidence-Based Medicine, Society of Thoracic Surgeons. The Society of Thoracic Surgeons practice guideline series: antibiotic prophylaxis in cardiac surgery, part II: antibiotic choice. Ann Thorac Surg. 2007;83: 1569-76.

27. Horvath KA, Acker MA, Chang H, Bagiella E, Smith PK, Iribarne A, et al. Blood transfusion and infection after cardiac surgery. Ann Thorac Surg. 2013;95: 2194-201.

28. Russell GN, Yam PC, Tran J, Innes P, Thomas SD, Berry PD, et al Gastroesophageal reflux and tracheobronchial contamination after cardiac surgery: should a nasogastric tube be routine? Anesth Analg. 1996;83:228-32.

29. Joshi N, Localio AR, Hamory BH. A predictive risk index for nosocomial pneumonia in the intensive care unit. Am J Med. 1992;93:135-42.

Key Words: pneumonia, infections, cardiac surgery, outcomes, quality improvement 


\section{APPENDIX E1. PRIMARY ENDPOINT DEFINITION AND VARIABLES FOR COX REGRESSION \\ Definition of Pneumonia}

To be classified as pneumonia, the following criteria must have been met (adapted from the Centers for Disease Control and Prevention/National Healthcare Safety Network guidelines for the clinical diagnosis of pneumonia):

1. At least one or more chest radiographs no earlier than 2 days after surgery with at least 1 of the following: (a) new or progressive and persistent infiltrate, (b) consolidation, or (c) cavitation.

2. Patient has at least 1 of the following signs or symptoms: fever $\left(>38^{\circ} \mathrm{C}\right)$ with no other recognized cause, leukopenia $\left(<4000\right.$ white blood cells $\left./ \mathrm{mm}^{3}\right)$ or leukocytosis $\left(\geq 12,000\right.$ white blood cells $\left./ \mathrm{mm}^{3}\right)$, or altered mental status with no other recognized cause (for patients $\geq 70$ years old) and at least 2 of the following: (a) new onset of purulent sputum or change in character or sputum or increased respiratory secretions or increased suctioning requirements; (b) new onset or worsening cough, or dyspnea, or tachypnea; (c) rales or bronchial breath sounds; (d) worsening gas exchange (eg, oxygen desaturations, increased oxygen requirements, or increased ventilator demand)

Variables tested in the Stage 1 baseline risk model and their crude association with pneumonia

\begin{tabular}{|c|c|c|c|}
\hline $\begin{array}{c}\text { Baseline and operative } \\
\text { characteristics }\end{array}$ & $\begin{array}{l}\text { Pneumonia, } \\
\text { n (\%) }\end{array}$ & $\begin{array}{c}\text { Unadjusted } \\
\text { HR }(95 \% \text { CI })\end{array}$ & $\begin{array}{c}P \\
\text { value* }\end{array}$ \\
\hline \multicolumn{4}{|l|}{ Demographics } \\
\hline Age, y & & $1.02(1.00-1.03)$ & .02 \\
\hline Sex & & $1.07(0.73-1.56)$ & .73 \\
\hline Male & $84(2.4)$ & & \\
\hline Female & $39(2.3)$ & & \\
\hline Race & & $0.56(0.38-0.85)$ & .01 \\
\hline White & $92(2.1)$ & & \\
\hline Nonwhite & $31(3.7)$ & & \\
\hline BMI, $\mathrm{kg} / \mathrm{m}^{2}$ & & $1.00(0.96-1.03)$ & .83 \\
\hline Insurance & & & .59 \\
\hline Medicaid & $8(3.4)$ & $1.79(0.73-4.38)$ & \\
\hline Medicare & $51(2.6)$ & $1.38(0.74-2.59)$ & \\
\hline Government (other) & $12(1.9)$ & 1.00 (ref) & \\
\hline Private & $45(2.1)$ & $1.12(0.59-2.11)$ & \\
\hline None/self & $7(2.7)$ & $1.41(0.55-3.59)$ & \\
\hline \multicolumn{4}{|l|}{ Baseline laboratory values } \\
\hline WBC, $\times 10^{3} / \mathrm{mL}$ & & $1.03(0.99-1.07)$ & .19 \\
\hline Creatinine, $\mathrm{mg} / \mathrm{dL}$ & & $1.14(1.07-1.22)$ & $<.001$ \\
\hline Hemoglobin, g/dL & & $0.80(0.73-0.88)$ & $<.001$ \\
\hline \multicolumn{4}{|l|}{ Cardiac morbidity } \\
\hline Hypertension & & $1.60(1.01-2.54)$ & .04 \\
\hline Yes & $101(2.6)$ & & \\
\hline No & $22(1.7)$ & & \\
\hline
\end{tabular}

(Continued)
(Continued)

\begin{tabular}{|c|c|c|c|}
\hline $\begin{array}{c}\text { Baseline and operative } \\
\text { characteristics }\end{array}$ & $\begin{array}{c}\text { Pneumonia, } \\
\text { n (\%) } \\
\end{array}$ & $\begin{array}{c}\text { Unadjusted } \\
\text { HR }(95 \% \text { CI })\end{array}$ & $\begin{array}{c}P \\
\text { value* }^{*} \\
\end{array}$ \\
\hline Heart failure & & $2.19(1.53-3.11)$ & $<.001$ \\
\hline Yes & $58(3.9)$ & & \\
\hline No & $65(1.8)$ & & \\
\hline Previous cardiac surgery & & $1.98(1.35-2.89)$ & $<.001$ \\
\hline Yes & $38(4.0)$ & & \\
\hline No & $85(2.0)$ & & \\
\hline \multicolumn{4}{|l|}{ Noncardiac morbidity } \\
\hline Corticosteroids & & $2.82(1.52-5.21)$ & .001 \\
\hline Yes & $11(6.3)$ & & \\
\hline No & $112(2.3)$ & & \\
\hline Diabetes $\dagger$ & & $1.05(0.69-1.60)$ & .81 \\
\hline Yes & $29(2.5)$ & & \\
\hline No & $94(2.4)$ & & \\
\hline History of smoking & & & .06 \\
\hline No & $52(1.9)$ & 1.00 (ref) & \\
\hline Current & $23(3.4)$ & $1.76(1.08-2.88)$ & \\
\hline Former & $47(2.7)$ & $1.38(0.93-2.05)$ & \\
\hline COPD & & $2.58(1.75-3.78)$ & $<.001$ \\
\hline Yes & $37(5.0)$ & & \\
\hline No & $86(1.9)$ & & \\
\hline Cerebrovascular accident & & $1.06(0.59-1.88)$ & .85 \\
\hline Yes & $13(2.5)$ & & \\
\hline No & $110(2.4)$ & & \\
\hline Peripheral vascular disease & & $1.59(0.97-2.59)$ & .06 \\
\hline Yes & $19(3.6)$ & & \\
\hline No & $104(2.2)$ & & \\
\hline \multicolumn{4}{|l|}{ Operative } \\
\hline Surgery time, hours & & $1.44(1.31-1.58)$ & $<.001$ \\
\hline Bypass & & $1.10(0.58-2.11)$ & .77 \\
\hline Yes & $113(2.4)$ & & \\
\hline No & $10(2.2)$ & & \\
\hline Circulatory arrest & & $2.19(1.21-3.97)$ & .01 \\
\hline Yes & $12(4.9)$ & & \\
\hline No & $111(2.3)$ & & \\
\hline Sternotomy & & $0.78(0.46-1.32)$ & .35 \\
\hline Full & $107(2.5)$ & & \\
\hline Not full & $16(1.9)$ & & \\
\hline Surgery type & & & .08 \\
\hline Elective & $80(2.1)$ & 1.00 (ref) & \\
\hline Urgent & $38(3.1)$ & $1.50(1.02-2.20)$ & \\
\hline Emergent & $5(3.6)$ & $1.72(0.70-4.22)$ & \\
\hline Procedure & & $4.99(2.84-8.78)$ & $<.001$ \\
\hline LVAD/Tx & 13 (10.7) & & \\
\hline All others & $110(2.2)$ & & \\
\hline Previous IABP & & $1.51(0.55-4.10)$ & .42 \\
\hline Yes & $4(3.5)$ & & \\
\hline No & $119(2.4)$ & & \\
\hline
\end{tabular}

Variables not used because of small cell counts: The sternum was not closed for 16 patients, only 1 of whom developed pneumonia. Variables not used because of excessive missing data: ejection fraction. $H R$, Hazard ratio; $C I$, confidence interval; $B M I$, body mass index; $W B C$, white blood cell; $C O P D$, chronic obstructive pulmonary disease; $L V A D / T x$, left ventricular assist device or heart transplant surgery; IABP, intraaortic balloon pump. *Based on competing risk model with time to pneumonia as outcome, baseline factors as covariates, and death as competing risk. †Insulin or oral medications. 
Variables tested in the Stage 2 process of care model and their crude association with pneumonia

\begin{tabular}{|c|c|c|c|}
\hline Management practice & $\begin{array}{c}\text { Pneumonia, } \\
\text { n }(\%) \\
\end{array}$ & $\begin{array}{c}\text { Unadjusted } \\
\text { HR }(95 \% \text { CI) } \\
\end{array}$ & $\begin{array}{c}P \\
\text { value }^{*}\end{array}$ \\
\hline $\begin{array}{l}\text { Correct timing of preoperative } \\
\text { antibiotics before } \\
\text { surgery }\end{array}$ & & $0.76(0.48-1.22)$ & .26 \\
\hline Yes & $102(2.3)$ & & \\
\hline No & $21(3.0)$ & & \\
\hline $\begin{array}{l}\text { Nasopharyngeal } \\
\text { decontamination }\end{array}$ & & $0.80(0.56-1.15)$ & .24 \\
\hline Yes & $51(2.1)$ & & \\
\hline No & $71(2.6)$ & & \\
\hline Scrubbing of surgical site & & & .01 \\
\hline No & $5(6.4)$ & 1.00 (ref) & \\
\hline Yes with chlorhexidine & $106(2.6)$ & $0.39(0.16-0.96)$ & \\
\hline Yes without chlorhexidine & $12(1.3)$ & $0.20(0.07-0.55)$ & \\
\hline $\begin{array}{l}\text { Appropriate dosing of } \\
\text { intraoperative antibiotics }\end{array}$ & & $0.47(0.21-1.06)$ & .07 \\
\hline Yes & $117(2.3)$ & & \\
\hline No & $6(4.9)$ & & \\
\hline $\begin{array}{l}\text { Postoperative antibiotics } \\
\text { duration }\end{array}$ & & & $<.001$ \\
\hline$\leq 24 \mathrm{~h}$ & $48(1.8)$ & $1.16(0.75-1.79)$ & \\
\hline $24-48 \mathrm{~h}$ & $34(1.6)$ & $1.00(\mathrm{ref})$ & \\
\hline$>48 \mathrm{~h}$ & $41(9.4)$ & $6.09(3.87-9.59)$ & \\
\hline Second-generation CEPH & & $0.68(0.47,0.98)$ & .04 \\
\hline Yes & $46(1.9)$ & & \\
\hline No & $77(2.8)$ & & \\
\hline Ventilation & & & $<.001$ \\
\hline$\leq 24 \mathrm{~h}$ & $46(1.1)$ & 1.00 (ref) & \\
\hline $24-48 \mathrm{~h}$ & $32(4.7)$ & $4.25(2.71-6.68)$ & \\
\hline$>48 \mathrm{~h}$ & $43(11.1)$ & $10.36(6.84-15.67)$ & \\
\hline NG tube & & $1.84(1.15-2.94)$ & .01 \\
\hline Yes & $102(2.7)$ & & \\
\hline No & $21(1.5)$ & & \\
\hline Femoral line & & $3.58(1.13-11.32)$ & .03 \\
\hline Yes & $3(8.1)$ & & \\
\hline No & $120(2.3)$ & & \\
\hline More than 1 central line & & $2.39(1.56-3.67)$ & $<.001$ \\
\hline Yes & $27(4.9)$ & & \\
\hline No & $96(2.1)$ & & \\
\hline Glucose management & & $1.21(0.85-1.73)$ & .30 \\
\hline Hyperglycemic & $58(2.6)$ & & \\
\hline Nonhyperglycemic & $63(2.2)$ & & \\
\hline PRBC, unit & & $1.30(1.24-1.36)$ & $<.001$ \\
\hline Platelet & & $2.13(1.50-3.04)$ & $<.001$ \\
\hline Yes & $60(3.7)$ & & \\
\hline No & $63(1.8)$ & & \\
\hline
\end{tabular}

Variable not used because of small cell counts: (1) Elevation of head of bed: Among the 18 patients who did not have elevation of head of bed, only 1 developed pneumonia. (2) Aspiration of secretions: Among the 201 patients who did not have aspiration of secretions, only 1 developed pneumonia. $H R$, Hazard ratio; $C I$, confidence interval; $C E P H$, cephalosporin; $N G$, nasogastric tube; $P R B C$, packed red blood cells. *Based on competing risk model with time to pneumonia as outcome, management practices as covariates, and death as competing risk.

\section{APPENDIX E2. CTSN MEMBERS}

The members of the Cardiothoracic Surgical Trials Network (CTSN) involved in this study were as follows:

National Heart, Lung, and Blood Institute: Marissa A. Miller, Wendy C. Taddei-Peters, Dennis Buxton, Ron Caulder, Nancy L. Geller, David Gordon, Neal O. Jeffries, Albert Lee;

National Institute of Neurological Disorders and Stroke: Claudia S. Moy;

Canadian Institutes of Health Research: Ilana Kogan Gombos, Jennifer Ralph;

Network Chairs: Christiana Care Health System, Timothy J. Gardner, (Chair); Brigham and Women's Hospital, Patrick T. O'Gara, (Co-Chair);

Data Coordinating Center: International Center for Health Outcomes and Innovation Research at Icahn School of Medicine at Mount Sinai, Annetine C. Gelijns, Michael K. Parides, Deborah D. Ascheim, Alan J. Moskowitz, Ellen Moquete, Eric A. Rose, Melissa Chase, Yingchun Chen, Rosemarie Gagliardi, Lopa Gupta, Edlira Kumbarce, Ron Levitan, Karen O'Sullivan, Milerva Santos, Alan Weinberg, Paula Williams, Carrie Wood, Xia Ye;

Core Clinical Site Investigators: Cleveland Clinic Foundation, Eugene H. Blackstone (PI), A. Marc Gillinov, Pamela Lackner, Leoma Berroteran, Diana Dolney, Suzanne Fleming, Roberta Palumbo, Christine Whitman, Kathy Sankovic, Denise Kosty Sweeney; National Heart, Lung, and Blood Institute (NHLBI) Clinical Research Scholars: Gregory Pattakos, Pamela A. Clarke; Columbia University, Michael Argenziano (PI), Mathew Williams, Lyn Goldsmith, Craig R. Smith, Yoshifumi Naka, Allan Stewart, Allan Schwartz; Daniel Bell, Danielle Van Patten; Duke University, Peter K. Smith (PI), Stacey Welsh, John H. Alexander, Carmelo A. Milano, Donald D. Glower, Joseph P. Mathew, J. Kevin Harrison; NHLBI Clinical Research Scholars: Mark F. Berry, Cyrus J. Parsa, Betty C. Tong, Judson B. Williams; East Carolina Heart Institute, T. Bruce Ferguson (PI), Alan P. Kypson, Evelio Rodriguez, Malissa Harris, Brenda Akers, Allison O'Neal; Emory University, John D. Puskas (PI), Vinod H. Thourani, Robert Guyton, Jefferson Baer, Kim Baio, Alexis A. Neill; Montefiore-Einstein Heart Center, New York, NY, Robert E. Michler (PI), David A. D'Alessandro, Joseph J. DeRose, Jr, Daniel J. Goldstein, Ricardo Bello, William Jakobleff, Mario Garcia, Cynthia Taub, Daniel Spevak, Roger Swayze; Montreal Heart Institute, Louis P. Perrault (PI), Arsène-Joseph Basmadjian, Denis Bouchard, Michel Carrier, Raymond Cartier, Michel Pellerin, Jean François Tanguay, Ismael El-Hamamsy, André Denault, Jonathan Lacharité, Sophie Robichaud; National Institutes of Health Heart Center at Suburban Hospital, Keith A. Horvath (PI), Philip C. 
Corcoran, Michael P. Siegenthaler, Mandy Murphy, Margaret Iraola, Ann Greenberg; University of Pennsylvania, Michael A. Acker (PI), Y. Joseph Woo, Mary Lou Mayer; University of Virginia, Irving L. Kron (PI), Gorav Ailawadi, Karen Johnston, John M. Dent, John Kern, Jessica Keim Sandra Burks, Kim Gahring;

Protocol Review Committee: David A. Bull (Chair); Patrice Desvigne-Nickens, Executive Secretary; Dennis O. Dixon, Mark Haigney, Richard Holubkov, Alice Jacobs, Frank Miller, John M. Murkin, John Spertus, Andrew S. Wechsler;
Data and Safety Monitoring Board: Frank Sellke (Chair); Cheryl L. McDonald, Executive Secretary; Robert Byington, Neal Dickert, Dennis O. Dixon, John S. Ikonomidis, David O. Williams, Clyde W. Yancy;

Medical Monitors: James C. Fang, Wayne Richenbacher; Overall Event Adjudication Committee: Vivek Rao (Chair); Karen L. Furie, Rachel Miller, Sean Pinney, William C. Roberts;

Infection Event Adjudication Committee: Rachel Miller (Chair); Shirish Huprikar, Marilyn Levi. 